\title{
O POPULISMO COMO PROBLEMA JURÍDICO: IMPACTOS DO DISCURSO POPULISTA NO ESTADO DEMOCRÁTICO DE DIREITO
}

Giancarlo Montagner Copelli*

\begin{tabular}{l|l}
\hline RECEBIDO EM: & 15.3 .2021 \\
\hline APROVADO EM: & 30.3 .2021 \\
\hline
\end{tabular}

* Mestre (Unijuí) e doutor em Direito pela Universidade do Vale do Rio dos Sinos (Unisinos). Atualmente em estágio pós-doutoral com bolsa Capes/PNPD, vinculado ao “Dasein”, no PPG Direito Unisinos. E-mail: giancarlocopelli@ yahoo.com.br 
- RESUMO: Este artigo pretende analisar os impactos do discurso populista no Estado Democrático de Direito. Para tal, a metodologia utilizada será a fenomenológica-hermenêutica, dividindo o trabalho em duas partes. A primeira volta-se à conceituação do referido fenômeno político, estruturalmente vinculado à democracia e à institucionalidade, a partir de demandas populares não satisfeitas. A segunda parte debruça-se sobre o Estado Democrático e a crise verificada no Direito enquanto produto do Estado, compreendido como espaço não apenas de produção normativa, mas, também, de acesso a um conjunto de demandas. É, pois, não apenas brecha ao surgimento do discurso populista aos olhos desse estudo - sobretudo, em países de modernidade tardia -, como, também forma de organização social e política a ser por ele ainda mais enfraquecida. Por fim, conclui-se que o populismo projeta-se como uma tentativa, entre outros fatores, de reescrever Constituições, atuando à margem das instituições. É, por isso, mais que um problema sociológico ou afeito sobremaneira às ciências políticas. É um problema jurídico.

palaVRas-chave: democracia; Estado Democrático de Direito; populismo.

\section{POPULISM AS A LEGAL PROBLEM: IMPACTS OF POPULIST SPEECH IN THE DEMOCRATIC STATE OF LAW}

- ABStRACT: This paper intends to analyze the impacts of populist discourse in the Democratic State of Law. For this, it is divided into two parts. The first turns to the conceptualization of this political phenomenon, structurally linked to democracy and institutionalist, based on unmet popular demands. The second part deals with the Democratic State and the crisis verified in the Law as a product of the State, understood as a space not only of normative production, but also of access to a set of demands. It is, therefore, not only a breach to the emergence of populist discourse in the eyes of this study - especially in countries of late modernity - as well as a form of social and political organization to be further weakened by it. After all, it is concluded that populism is projected, especially, as an attempt, among other factors, to rewrite Constitutions, acting at the margin of institutions. The method is phenomenological-hermeneutic.

- Keywords: democracy; democratic state of law; populism. 


\section{Considerações iniciais}

Testemunha da Bulgária comunista (1946-1990), o historiador Tzvetan Todorov (2012), ao ensaiar quais seriam os inimigos à democracia na contemporaneidade, aponta o dedo não para as temidas ameaças externas ao modelo, caso do próprio comunismo que viu apoderar-se de seu país de origem durante sua juventude, por exemplo, mas para um fenômeno interno - íntimo, portanto -, possível, sobretudo, a partir das regras do jogo democrático: o fortalecimento de partidos de viés populista.

Do tipo autoritário dos anos $1930^{1}$ ao modelo observado na Europa a partir do fim da Guerra Fria $^{2}$ - com a queda do Muro de Berlim e a necessidade, à margem de um rival comunista, ainda de um adversário -, foi esse mesmo fenômeno, talvez em escala global, que abriu, no debate político da atualidade, um amplo catálogo de interrogações: mais bem acabado produto de uma crise da democracia representativa em uma escala sem precedentes? Inevitável reflexo de outra crise - cíclica -, relacionada ao capitalismo que sustenta os modelos de bem-estar nessas mesmas experiências democráticas? Ou, a partir desse mesmo enredo econômico, saldo típico da dependência política dos resultados da economia? Essas são algumas questões, sem dúvida importantes, mas talvez não as mais caras a este estudo, entre as muitas possibilidades de abordagem.

O populismo, conceituado mínima e introdutoriamente como tentativa de abolir as distâncias entre o povo e o poder por meio de um discurso demagógico, é fácil de assimilar e, ao mesmo tempo, difícil ou impossível de se realizar (COPELLI, 2012; 2015); parece fragilizar conquistas alinhadas ao Estado Democrático de Direito na tentativa de agradar maiorias. Eis o ponto em que esta possibilidade investigativa se orienta, buscando, frente a breves apontamentos de base e contexto global, fornecer horizontes comuns de sentido que permitam enxergar a questão sob o prisma da atualidade brasileira, remanejando-o, ainda, como um problema jurídico.

Nesse sentido, compreende-se, desde já, que o populismo é, para além dessas mesmas conceituações mínimas, mais que um discurso à margem das instituições atrás da capitalização política. Embora persiga tal objetivo - ou, como saldo, com ele se encontre-, o populismo toca a superfície mais sensível de problemas reais típicos do chamado grande número, e seus protagonistas são hábeis atores em identificá-los em uma espécie

1 Como se pode pensar, no Brasil, o Estado Novo de Vargas, de 1937 a 1946.

2 Período conhecido, popularmente, como aquele marcado por um conflito indireto entre Estados Unidos e União Soviética, entre 1945 e 1991. 
de vácuo institucional. De outro modo: ao lado da solução mítica que lhe encerra - e que, em boa medida, o caracteriza -, o discurso populista percebe os pontos de insuficiência institucional da corrente orientada como racional e, a partir disso, promete a solução, como vem se colocando, no Brasil, uma espécie de marcha contra a corrupção ou contra a criminalidade, a qualquer preço, por exemplo. Daí, não apenas sua proximidade com a democracia como, mais que isso, seus riscos. Afinal, justamente nesse regime, é impossível pensar o poder - seja do ponto de vista de quem o almeja, seja sob a procura exclusiva de sua manutenção - distanciando-se dos anseios e necessidades da população(WEFFORT, 2003). Com isso, é possível ver, em escala global, discursos caros à Esquerda na agenda da Direita e vice-versa, com adaptações que justificam guinadas ideológicas ao redor do globo.

Nesse sentido, ainda introdutoriamente, exemplos não faltam. Na França, Marine Le Pen, da Rassemblement National (antiga Front National), ${ }^{3}$ propôs Estado de Bem-estar Social (apenas) para os franceses. Ou seja, uma clara política de preferência nacional (CARVALHO, 2016), em discurso nacionalista, conservador e protecionista típico da Direita, mas flertando com um ideário de igualdade, de intervenção estatal comum à Esquerda. Nos Estados Unidos da América, tem-se outro exemplo com o ex-presidente Donald Trump e a emergência de muros para a proteção dos empregos de um mundo congelado nos Anos de Ouro do Capitalismo - e que, por óbvio, jamais retornará, como apontam uma série de estudos acadêmicos voltados a projeções acerca das profundas transformações pelas quais passa o mundo do trabalho, como, por todos, o de Carl Frey e Michael Osborne (2017). São exemplos, assim como localmente o Brasil de Vargas, Jânio, Collor e Lula, ${ }^{4}$ recorrentes personagens apontadas pela literatura acadêmica em História, Ciência Política e Economia, entre outras áreas, como carismáticos líderes populistas frente às suas cruzadas contra o inimigo externo, o funcionalismo público, os marajás e as elites brancas, respectivamente, assim como, provavelmente, será Jair Bolsonaro ou o ex-governador do estado do Rio de Janeiro, Wilson Witzel, no futuro, e o embate contra a corrupção, o comunismo ou a criminalidade, entre outras saídas míticas a problemas complexos no Brasil, as insuficiências de um Estado Fiscal a exemplo.

Evidentemente, essas emblemáticas personagens políticas não são citados sem desconhecer o risco da crítica - já bem lembrado por Angela de Castro Gomes - por

3 Partido político.

4 Aqui, ver as análises de José Murilo de Carvalho (2002), Francisco Weffort (2003), Marques e Mendes (2006) e Gilberto Bercovici e Luís Fernando Massonetto (2004). 
“incompletude ou por 'má' compreensão, por adesão ou por rejeição” (1996) a atores políticos pinçados em todos os espaços político-ideológicos. Assumindo-o, portanto, adverte-se que a proposta, entretanto, é a análise do impacto do discurso que sustenta tal fenômeno político no Estado Democrático de Direito, e não do enquadramento, por características de proximidade, de determinadas lideranças políticas a uma espécie de conjunto dos populistas. Ou seja, interessa o conceito - e não as personagens - para o desenvolvimento dessa proposta. Assim, ressalva feita, é a partir desta breve exposição de cenário - contexto para se pensar o fenômeno do populismo como problema jurídico e como produto da crise do Direito -, que este texto se projeta.

Divide-se em dois pontos, considerados angulares ao ensaio de um desfecho: o primeiro é assentar o conceito ao fenômeno que sustenta a discussão e o segundo envolve, a partir de exemplo recente, brevíssimo escorço voltado ao Estado Democrático eà crise verificada no Direito enquanto produto do Estado, compreendido como espaço não apenas de produção normativa, mas, ainda, de acesso a um conjunto de demandas, fragilizado por uma série de influxos neoliberais, que também tenta acessá-lo.

O populismo é, assim, mutuamente um produto da crise e um fator a alimentá-la. Afinal, como poderá ser verificado ao longo deste texto, seu discurso, ao propor soluções míticas, projeta o fim das instituições democráticas e mina a burocracia necessária à impessoalidade - que, entre outros fatores, caracteriza o Estado Democrático de Direito. E, ao alimentar toda sorte de ativismos - como rápido caminho à satisfação popular - procura, também, reescrever a Constituição.

Buscando delimitar a maneira, os instrumentos e outros fatores que envolvem esta pesquisa, basicamente bibliográfica e qualitativa, esclarece-se que a metodologia aqui empregada terá como abordagem o método fenomenológico-hermenêutico. Tal é embasado a partir de Martin Heidegger e Hans-Georg Gadamer, ${ }^{5}$ cuja principal contribuição é justamente romper com as tradicionais estruturas metodológicas à luz da modernidade inaugurada com Descartes. ${ }^{6}$ Não há, a partir desses autores, um caminho

5 "Heidegger somente entra na problemática hermenêutica das ciências históricas com a finalidade ontológica de desenvolver, a partir delas, a pré-estrutura da compreensão. Já nós [Gadamer, falando na primeira pessoa do plural], pelo contrário, perseguimos a questão de como, uma vez liberada das inibições ontológicas do conceito de objetividade da ciência, a hermenêutica pôde fazer jus à historicidade da compreensão" (GADAMER, 2008, p. 400, colchetes nossos).

6 Projetando um "erro fundamental do desenvolvimento do conceito de sujeito desde Descartes", Heidegger observa que, com "ele começa propriamente a fatalidade da filosofia moderna, porque nele o ego, o eu é de tal forma empobrecido que não é mais nenhum sujeito. O ego sum em Descartes é sem o ser junto a..., sem o ser-um-com-o-outro. Pois Descartes não chega nem mesmo a colocar a pergunta fundamental, digo, ele não chega nem mesmo a questionar como esse ego é, o que significa esse sum no ego sum em contraposição ao ser, por exemplo, da res extensa” (HEIDEGGER, 2008, p. 124-125, grifos do autor). 
metodológico definitivo, uma vez que não se pode apreender ou dominar os elementos nele envolvidos (STEIN, 1991).

\section{Populismo: a demanda reprimida e o mítico à margem da institucionalidade}

Em El populismo como concepto (2003, p. 1), Guy Hermet interroga, por uma imaginada substância do fenômeno populista, para, em seguida, sentenciar: não há um consenso sobre a definição desse fenômeno político. Envolto em uma combinação, isto é, em uma possibilidade de combinações bastante extensa, em níveis tanto temporais quanto espaciais, o populismo ficaria, assim, situado em uma moldura bastante ampla possivelmente ampla demais - para poder ser conceituado. De todo modo, Hermet também acena a uma espécie de mínimo comum a todas as experiências consideradas nesse espectro. E, por conseguinte, assentando-o na ausência de coesão nas comunidades nacionais, projeta o populismo como uma "controversa promessa de satisfação imediata”, que, aos propósitos deste ensaio, figura como importante ponto de partida. Afinal, como se verá adiante, permite a vinculação do fenômeno a demandas populares, dirigidas à institucionalidade, frustradas, como vai propor, em apertada síntese, Ernesto Laclau (2005).

Éa partir desse mínimo, portanto, verificável nas mais diversificadas possibilidades de se apontar o populismo, seja qual for a circunstância, o tempo e o local da experiência, que se pode compreendê-lo a partir da historicidade que o molda - e que permite desvelá-lo, por isso, mergulhado sempre em um contexto. Amolda-se, assim, não apenas àquela sucinta conceituação, projetada para introduzir a discussão a que este texto se propõe, mas permite, também, a associação a novos e distintos fatores, determinados por tempo e circunstância próprios a uma determinada comunidade política.

É possível admitir, por isso, conceituações mais abrangentes, como a de Michel Wieviorka (1993), como um importante complemento. Embora esse autor também enfatize a dificuldade em assentar um conceito ao fenômeno, ele pontua, igualmente, algo que caracteriza - ou pode caracterizar - a sua unidade: o sentimento de distância, que pode ou não ser real, entre o poder político e econômico e o povo de uma determinada localidade. Esse sentimento pode ser localizado entre os trabalhadores excluídos de um mercado laboral envolto em transformações de contornos ainda imprevisíveis contudo, aparentemente permanentes -, caso dos EUA, por exemplo, mas acalenta- 
dos, como exposto em introdutório exemplo, pelo discurso que promete fazer voltar o tempo da História. ${ }^{7} \mathrm{Na}$ Europa, por seu turno, o mesmo sentimento pode ser aquele a mover o indivíduo que vê, nos fluxos migratórios, uma ameaça a sua cultura ${ }^{8}$ - e, no discurso que promete fazer voltar uma pretensa homogeneidade étnica, a ponte entre a sua vontade e o poder que permite realizá-la. Mais: é o sentimento do sujeito que, no Brasil, diante de indistinta criminalidade, por exemplo, vê em radicalizados discursos a solução para os mais significantes problemas nessa seara.

Há, portanto, demandas reais, legítimas ou não, endereçadas à institucionalidade, frustradas ou reprimidas por uma série de razões. O populismo volta-se a essas mesmas reivindicações e seu discurso promete, miticamente, fazer a ligação, em tese perdida, entre vontade - ou necessidade - e poder, entre o demos e o poder, ou seja, entre os elementos que, conjugados, permitem desvelar o político - no sentido de fenômeno - nas democracias, como sugere Francis Wolf (2003), ao propor essa combinação de elementos. Não por acaso, diz Wieviorka, "um mesmo impulso populista pode muito bem ter a sua vertente progressista e a sua vertente conservadora ou reacionária, ou, ainda, evoluir no tempo em favor da predominância de uma ou de outra”. Não há domínio de uma ou outra ideologia política, e, justamente por isso, é adaptável a todos os espectros políticos. É ao “mesmo tempo tradicional e hostil à modernidade” (WIEVIORKA, 1993, p. 97).

Eis o ponto. Para além de seu deslocamento ideológico e sua inclinação ao alinhamento de um sentimento comum ao grande número, fator este relevante àqueles que pretendem ascender e manter o poder nas democracias, o populismo germina, em assertiva sustentada na proposta laclauniana - sempre a partir de necessidades, anseios e vontades localizadas para além de saídas institucionais ainda não verificadas no já referido contexto de crise -, como questões envolvendo saúde pública, com altos custos

7 Durante sua campanha eleitoral, o então candidato à presidência dos Estados Unidos, Donald Trump, prometeu "implementar a independência energética e criar empregos na exploração de carvão, ao derrubar a maior parte da regulamentação de seu antecessor, Barack Obama, sobre mudança climática”. Em seu discurso, encarnou a demanda reprimida, e, magicamente, sentenciou: "Estamos colocando um fim ao roubo da prosperidade americana e revivendo nossa amada economia”, acrescentou Trump. "Os mineiros me contaram do ataque a seus empregos e eu fiz essa promessa. Eles voltarão ao trabalho” (ESTADO DE S. PAULO, 2019).

8 Em 2018, a imprensa europeia mostrou-se preocupada com a escalada dos discursos populistas, encarnando uma pretensa reivindicação por homogeneidade étnica. "A imprensa francesa demonstra preocupação [...] com o aumento da xenofobia na Europa. O retorno do populismo, alimentado pela crise migratória, tem alimentado manifestações racistas em vários países do bloco, algo que não se via há mais de 70 anos. Em seu editorial, o jornal progressista Libération diz que a Europa enfrenta um verdadeiro incêndio. Os valores que fizeram a força do continente no pós-guerra - o respeito à democracia, aos direitos humanos, a abertura ao outro, a defesa da igualdade - estão derretendo, em meio à fúria incendiária dos populistas” (G1, 2019). 
ao Estado, em hipótese mais alinhada à Esquerda, por exemplo, ou que esbarram nos limites impostos por democráticos componentes contramajoritários, e, portanto, não podem ser realizados a partir das instituições - a menos que deformadas -, em saída mais alinhada à Direita. Eis o seu solo fértil: a demanda frustrada, seja qual for a inclinação ideológica, como projeta Ernesto Laclau (2005).

Não por acaso, Ricardo Luiz de Souza (2004, p. 1), em texto voltado a estudar o populismo "tendo como referência sua diversidade", vai lembrar que sua base não se forma a partir de uma "visão articulada da sociedade”, mas de um “conjunto de insatisfações e desejos de mudança dispersos”. Earremata: “O populismo é, simplesmente, contra ‘isso que está aí, e as reformas político-sociais por ele propostas tendem a ser tão vagas quanto o que deve ser mudado". Nesse contexto, substituindo vagueza reformista por um forte componente de transformação social, acenando positivamente ao fenômeno do populismo, portanto, Laclau claramente o projeta como uma bem-vinda - embora não em sua forma, digamos, pura - tensão entre institucionalismo versus populismo. O resultado que se forma a partir daí, claro, é uma desvalorização da política, porque a mudança, seja ela qual for, vai depender da atuação do líder - o indivíduo capaz de eliminar a distância entre povo e poder de que fala Wieviorka -, observado, aqui, como o vínculo possível entre o concreto e o desejo, entre a demanda e sua realização, ocupando o lugar da institucionalidade. Afinal, é justamente isso: o populismo se opõe às instituições.

Como dito introdutoriamente, esse estado de coisas não se dá fora de um contexto, e localiza-se como resposta a problemas reais. Para Laclau (2005), são essas reivindicações por demandas que correspondem ao primeiro estágio da lógica populista, e que, ao menos nesse aspecto, parece relevante a este estudo. Afinal, endereçada inicialmente às instituições, a demanda frustrada torna-se reivindicação não mais somente em favor da própria demanda, mas, também, contra a instituição - como se vê, por exemplo, na narrativa que conjuga ST F e corrupção na mesma frase. Como refere Margaret Canovan (1999) em discurso semelhante à proposta laclauniana, é, o populismo, contra a estrutura de poder estabelecida. Há, pois, uma lacuna entre o povo, que reivindica, e o poder, organizado institucionalmente. A condição de possibilidade para o seu surgimento, para a sua emergência, portanto, é uma espécie de vazio institucional. Em apertada síntese, podemos dizer, então, que o discurso populista se instala em um ambiente de crise institucional e se coloca contra a institucionalidade que organiza o poder nas sociedades democráticas. Democracia, instituições e populismo, portanto, caminham lado a lado em um intrincado jogo de tensões. 
Assim, assentada dessa maneira, a lógica populista pode significar não apenas uma deformação do processo democrático - em que um líder encarna a vontade popular e canaliza-a para acessar e manter o poder por meio de um discurso mágico -, mas, também, essa mesma premissa associada às saídas a demandas reais e frustradas por uma enferrujada engrenagem institucional. Seria, dessa maneira, algo positivo, colocando-se acima da lei - ou seja, das instituições e suas regras de funcionamento - em nome do povo, na projeção de ruptura de Laclau. Mas eis aí a interrogação que move a segunda etapa deste ensaio: no Estado Democrático de Direito, ${ }^{9}$ não é a lei, entendida como Constituição, a linguagem pública ${ }^{10}$ voltada à instrumentalização da ação estatal na busca de seu próprio conteúdo dirigente? ${ }^{11}$

\section{O Estado Democrático, a defesa das regras do jogo e um exemplo à brasileira}

A questão que encerra o tópico anterior - alicerçada, especificamente, no viés laclauniano no que se refere às demandas não satisfeitas, sejam elas legítimas ou ilegítimas - dialoga não apenas com o fenômeno do populismo incrustado nos regimes democráticos, que representam respostas insuficientes a reivindicações dirigidas à institucionalidade, mas, ainda, ou mesmo antes, reflete a crise do Direito, como referido introdutoriamente. Afinal, se é na reivindicação frustrada que o populismo encontra seu solo fértil, formando a tríade também composta por democracia e instituições, seu espaço é aquele em que expressiva parcela dos dispositivos da Constituição não obteve, até hoje, efetivação.

9 Aopresente estudo, entende-se o Estado Democrático de Direito como aquele em que, na visão de Guillermo O’Donnell, "qualquer que seja a legislação existente, ela é aplicada de forma justa pelas instituições estatais pertinentes, incluindo, mas não exclusivamente, o Judiciário". Forma justa "é o exercício de que a aplicação administrativa ou a decisão judicial de normas legais sejam coerentes em casos equivalentes, independentemente de diferenças de classe, condição social ou poder dos participantes nesses processos, adotando procedimentos que são estabelecidos e conhecíveis por todos" (O’DONNELL, 1998, p. 41). Além disso, importa também aqui observá-lo como um “novo modelo que remete a um tipo de Estado em que se pretende precisamente a transformação em profundidade do modelo de produção capitalista e sua substituição progressiva por uma organização social de características flexivelmente sociais, para dar passagem, por vias pacíficas e de liberdade formal e real, a uma sociedade no qual se possam implantar superiores níveis reais de igualdades e liberdades" (STRECK, 2014).

10 No sentido wittgensteiniano da expressão, à luz com as “Investigações Filosóficas” de Wittgenstein (1999).

11 Compreendido, aqui, na clássica proposta de José Joaquim Gomes Canotilho (2001), em que as constituições dirigentes projetam Estados que intervenham ativamente, buscando transformar as sociedades em que esses mesmos textos constitucionais estão inseridos. As constituições dirigentes, por isso, não são apenas estatais, mas, também, sociais. Entende-se, ainda, que protagonismo é justificado pelo fato de que as "noções de constituição dirigente, de força normativa da Constituição, de Constituição compromissária, não podem ser relegadas a um plano secundário, mormente em um país como o Brasil” (STRECK, 2003, p. 259). 
Ou seja, enquanto reflexivo da crise do Direito, é, pois, também produto da prevalência do paradigma da filosofia da consciência, refratário à guinada linguístico-hermenêutica, ${ }^{12}$ de cunho objetificante, e da não existência de um Estado Social no país até hoje (STRECK; BOLZAN DE MORAIS, 2014). Embora Laclau perceba o fenômeno como importante ingrediente transformador das relações sociais contemporaneamente,${ }^{13}$ seu surgimento supõe, na verdade, um empobrecimento do papel da teoria constitucional. Afinal, nesse viés, a Constituição seria, e não mais que isso, apenas garantidora do acesso aos mecanismos de participação democrática no sistema. Nesse recorte, a partir dessa confusa combinação de fatores, o Direito e as instituições não seriam agentes transformadores no Constitucionalismo Contemporâneo, âmbito em que o Direito assume elevado grau de autonomia. ${ }^{14} \mathrm{E}$, justamente por isso, não à toa, a demanda, frustrada vai esperar a solução à reivindicação do líder e não do Direito democraticamente produzido e das instituições por ele balizadas.

Daí que a ausência de função social do Direito e, portanto, a sua (não) inserção no horizonte de sentido proporcionado pelo Estado Democrático de Direito, compreendido a partir das condições de possibilidade de sua existência, perde-se em meio a uma baixa constitucionalidade (STRECK, 2000), composta por um discurso jurídico alienado da condição histórica da sociedade brasileira. É, de modo muito sucinto, a negação da própria historicidade que nos molda.

Nesse sentido, não é desarrazoado referir, no contexto em que se verifica o fenômeno do populismo, o enfraquecimento do sentido da nossa Carta. Há uma corrupção da atividade interpretativa, a permitir uma espécie de reorganização de sentidos. Eé a partir dessa premissa que se pode projetar, também o populismo, como produto da prevalência do paradigma da filosofia da consciência - como parece figurar como bom exemplo a plataforma eleitoral - convertida em política de combate ao crime organizado no

12 Claramente, adota-se, aqui, a crítica de Lenio Streck (2014).

13 Na edição brasileira de On populist reason, Laclau (2013, p. 20, grifos do autor) observa que "quando um projeto de transformação social profunda começa a ser implementado, ele entrará em choque, em vários pontos, com a ordem institucional vigente, e esta terá de ser modificada mais cedo ou mais tarde”. O populismo, ao colocar-se contra as instituições, corresponderia, entre outros fatores, a um fator de transformação social.

14 Como referido no Dicionário de Hermenêutica de Streck (2017, p. 37-38), o "Constitucionalismo Contemporâneo é um fenômeno que surge no segundo pós-guerra. Essa expressão foi cunhada no livro Verdade e Consenso para superar as aporias das teorias neoconstitucionalistas [...] representa(ndo) uma blindagem às discricionariedades e aos ativismos". Nesse contexto, não se perde de vista, sobretudo, que o "aspecto material da constitucionalização do ordenamento consiste na conhecida recepção no sistema jurídico de certas exigências da moral crítica na forma de direitos fundamentais. Em outras palavras, o Direito adquiriu uma forte carga axiológica, assumindo fundamental importância a materialidade da Constituição". Éjustamente por isso que não se pode afastar o seu caráter, evidentemente, transformador. 
estado do Rio de Janeiro, de seu ex-governador, Wilson Witzel, afastado por corrupção. Ao propor o abate de indivíduos como política criminal, como cotidianamente fez em suas manifestações, ${ }^{15}$ ele desvinculou a atividade estatal, afinal, da Constituição. Longe da intersubjetividade que molda regimes democráticos, a ação do Estado era, assim, não mais que um ato de vontade.

Eis o ponto de conexão com a primeira parte deste estudo. No contexto em que as instituições figuram distantes das demandas sociais e, pior, no imaginário popular, apresentam-se como lócus privilegiado à prática criminosa, observa-se que esse mesmo imaginário aceita, em todos os níveis, portanto, uma indistinta discricionariedade de operadores do Direito, incluindo aí administradores, fazendo coro a uma espécie de contramedida ao famoso jargão em que a polícia prende e o juiz solta. É preciso, pois, outro ato discricionário, fazendo suceder, indistintamente à margem do texto constitucional, vontades de poder para dar conta do problema socialmente demandado. Énesse espaço que o discurso populista se insere, buscando atender a uma reivindicação frustrada (no exemplo utilizado, o institucional e insuficiente combate à criminalidade, sobretudo, nas metrópoles brasileiras), mediante uma solução não apenas mítica, rápida - a sumária execução de indivíduos, por meio das polícias militares -, mas, ainda, à margem das instituições, neste caso, a Defensoria Pública do Estado e a Secretaria de Segurança Pública do Estado. A criminalidade, ao atingir níveis cada vez maiores, sobretudo nos grandes centros urbanos, ${ }^{16}$ é um problema real, portanto, a abrir as portas ao discurso populista e sua mítica solução. Desvelados estão, pois, não apenas os seus espaço e contexto, mas, ainda, a tentativa de reescrever a Constituição para agradar maiorias.

Seguindo, é bem verdade que esse exemplo não é único, mas é angular, figurando, aqui, como uma espécie de tipo ideal. Diante do interesse do grande número e frente à reivindicação, em tese, frustrada - uma vez que a um episódio sucede outro, e parecem sem fim os cotidianos casos de violência retratados, sobretudo, em megalópoles, como o Rio -, o modo proposto por seu ex-governador para enfrentar a violência ignora a inexistência de pena capital no Brasil, como, ainda, o fato de ser vedada a introdução desse

15 Conforme a editorial de política de Universo Online (2019): “Em diversas oportunidades, Witzel defendeu que policiais atirem para matar ao verem criminosos armados, ainda que não haja risco iminente de confronto - condição necessária para configurar legítima defesa, segundo a legislação atual. Em novembro, logo após ser eleito, ele afirmou ao jornal $O$ Estado de S. Paulo que "a polícia vai fazer o correto: vai mirar na cabecinha e... fogo! Para não ter erro". 
tipo de sanção ao ordenamento pátrio, uma vez que, ao promulgar o Decreto no ${ }^{\circ} .678$, o Brasil passou a ser signatário da Convenção Americana de Direitos Humanos, pela qual "não se pode restabelecer a pena de morte nos Estados que a hajam abolido" (Art. 4º, 3).

Não à toa, não é reservado aos órgãos de segurança pública (Art. 144, CF/88), ainda que exerçam o policiamento ostensivo (caso das polícias militares), o direito de matar. ${ }^{17}$ Eis o ponto: a vida é, ademais, inviolável (Art. $5^{\circ}$, caput, CF), e ignorar esse pressuposto, incentivando o abate de indivíduos, ainda que sob o pretexto de combater a criminalidade em níveis alarmantes, é não apenas a desvinculação da política à Constituição como, ainda, uma tentativa de se reescrever o texto constitucional que, nunca é demais lembrar, foi democraticamente elaborado. É dizer: projetar política pública de combate à criminalidade por meio do extermínio é discricionariedade para além do permitido em âmbito executivo e legislativo. É, pois, repete-se, tentativa de reescrever a Constituição. Justamente por isso, entende-se que o populismo se projeta reflexivo também a essa crise - do Direito e da democracia -, mas não se coloca, claro, como resposta legítima a ela. Ao contrário, agrava-a. Afinal, como se viu anteriormente, ocorre à margem das instituições, e se dá, portanto, fora do jogo de linguagem ${ }^{18}$ que é o Direito.

É desse modo, portanto, que o discurso populista se coloca como um íntimo inimigo da democracia - para lembrar, mais uma vez, a inquietante expressão de Todorov (2012) -, acenando para significativos impactos no Estado Democrático de Direito. E isso porque, ao se projetar como uma tentativa de reescrever o sentido da Constituição, em que as propostas de Witzel são apenas um exemplo, ultrapassa os indispensáveis mecanismos de contenção do poder das maiorias, típicos do Estado Democrático de Direito.

Ainda que alinhado à demanda institucionalmente não satisfeita, o agir político não pode atentar contra as garantias constitucionais voltadas a limitar os excessos do Estado. Como bem sublinhado no segundo capítulo de Verdade e Consenso, Lenio Streck (2017, p. 87) destaca que "uma vontade popular majoritária permanente, sem freios contramajoritários, equivale à volonté générale, a vontade geral absoluta propugnada por Rousseau, que se revelaria, na verdade, em uma ditadura permanente”. Ou seja, a indiscriminada filiação à vontade popular, como forma de acessar e manter-se no poder, aproximando o demos da realização de seus desejos à margem dos necessários

17 Por certo não se desconhece as situações envolvendo legítima defesa ou o risco de morte de outrem, sob ameaça.

18 No sentido wittgensteiniano da expressão, à luz com as “Investigações Filosóficas” de Wittgenstein (1999). 
mecanismos contramajoritários, ignora a “essência do Estado de Direito”, que é, enfim, a “submissão do poder ao [próprio] Direito” (STRECK, 2017, p. 87).

\section{Considerações finais}

A tese que aqui se assenta é a de que o discurso populista, como aproximação ao interesse do grande número, a partir da hábil identificação das demandas populares não atendidas institucionalmente, coloca-se como uma espécie de ativismo, à margem daquele de cariz jurídico, ${ }^{19}$ mas, igualmente, nocivo à democracia: procura reescrever Constituições e ignora o traço contramajoritário que identifica, entre outros fatores, o Estado Democrático de Direito, opondo-se às instituições. É, por isso, também, um problema jurídico, ao colocar-se contra a estrutura de poder estabelecida (instituições) e aos princípios de uma determinada comunidade política, cristalizados constitucionalmente. Mais: é o inimigo íntimo da democracia, de que fala Todorov.

No exemplo discutido, o que se verificou foi um discurso mítico de combate à criminalidade, associado claramente a reivindicações inalcançadas institucionalmente - e arremessadas àqueles que, encarnando o desejo por mudança, acenam final e pessoalmente à realização da demanda. Sob um certo tipo de roupagem institucional - porque, de todo modo, é ainda por meio delas que tais mudanças se desvelam -, projeta-se uma espécie de reorganização do sentido constitucional, sobretudo, no que se refere aos indispensáveis mecanismos de contenção dos excessos do poder do Estado. É, pois, contexto alinhado ao que se viu: uma promessa de satisfação (HERMET, 2003), aproximando povo e poder (WIEVIORKA, 1993), contra isso que está ai ${ }^{20}$ (SOUZA, 2004), a partir de uma demanda não satisfeita (LACLAU, 2005, por todos). O impacto de discursos orientados nesse sentido, conclui-se, portanto, acena à fragilização do Estado Democrático de Direito.

19 No âmbito jurídico, tal fenômeno pode ser verificado por um conjunto de critérios indagativos, voltados a identificar, na decisão do magistrado, um ato de vontade - já verificado na "Teoria Pura do Direito" de Kelsen. São eles: primeiro, o Judiciário diante de um direito fundamental, subjetivamente exigível? Em situações similares, esse mesmo direito pode ser concedido a toda e qualquer pessoa que o pedir? No mais, é possível transferir recursos das outras pessoas para fazer aquela ou um grupo feliz, sem violar a isonomia no seu sentido substancial, já levando em conta toda a força do Estado Social previsto na Constituição? Cf. Streck (2013; 2017).

20 Esse "contra isso que está ai" pode muito bem ser compreendido como "contra a Constituição", replicando a tese corrente no imaginário de muitos cidadãos em que ‘direitos humanos só favorecem bandidos’ ou “direitos humanos só para humanos direitos”. Ver Copelli e Lima (2019). 


\section{REFERÊNCIAS}

BRASIL. Anteprojeto de Lei Anticrime. Disponível em: http://www.justica.gov.br/news/collective-nitf-content-1549284631.06/projeto-de-lei-anticrime.pdf. Acesso em: 4 fev. 2019.

BERCOVICI, G.; MASSONETTO, L. F. Os direitos sociais e as constituições democráticas brasileiras: breve ensaio histórico. In: RÚBIO, D. S.; FLORES, J. H.; CARVALHO, S. de. Direitos humanos e globalização: fundamentos e possibilidades desde a teoria crítica, v. 2, p. 510-528, 2004. p. 515-516. Disponível em: https://adrianonascimento.webnode.com.br/_files/200000198-3a08e3b02c/Bercovici\%20-\%20Massonetto.\%20Direitos\%20Socias\%20nas\%20Constitui\%C3\%A7\%C3\%B5es\%20Democr\%C3\%A1 ticas\%20do\%20Brasil.pdf. Acesso em: 9 jan. 2019.

BOLZAN de MORAIS, J. L. As crises do Estado contemporâneo. In: VENTURA, L. América Latina: cidadania, desenvolvimento e Estado. Porto Alegre: Livraria do Advogado, 1996.

BRASIL. Constituição da República Federativa do Brasil, de 1988. Disponível em: http://www.planalto. gov.br/ccivil_03/Constituicao/Constituicao.htm. Acesso em: 10 fev. 2019.

CANOVAN, M. Trust the people! Populism and the two faces of democracy. Political studies, v. 47, n. 1, p. 2-16, 1999. Disponível em: https://journals.sagepub.com/doi/abs/10.1111/1467-9248.00184?casa_token=jSamPL3-IuUAAAAA\%3AtSeVhvyoMUlqDyrBxJ-Pbm1vC_HZs6QSx3YIdMcVYJ3b52qBMRXWl6Azz7kxqe_k_JWVj4SdZv4H\&. Acesso em: 25 jan. 2019.

CARVALHO, J. Partidos de extrema-direita e a gestão da crise do asilo na Europa: o caso francês. Relações Internacionais (R: I), n. 50, p. 57-69, 2016. Disponível em: http://www.scielo.mec.pt/scielo.php?script=sci_arttext\&pid=S1645-91992016000200005. Acesso em: 21 fev. 2019.

CARVALHO, J. M. Cidadania no Brasil: o longo caminho. 3. ed. Rio de Janeiro, 2002.

CASTRO GOMES, A. O populismo e as ciências sociais no Brasil. Tempo, i, n. 2, p. 31-58, 1996. Disponível em: http://www.historia.uff.br/tempo/artigos_dossie/artg2-2.pdf. Acesso em: 18 fev. 2019.

COPELLI, G. M. Desigualdade social, democracia e direitos humanos: uma leitura da realidade brasileira. (Dissertação de Mestrado). Ijuí: Programa de Pós-Graduação em Direito da Universidade Regional do Noroeste do Estado do Rio Grande do Sul, 2014.

COPELLI, G. M. Do sangue ao mérito: os elementos de legitimação da desigualdade no Brasil e as possibilidades de superação pela via democrática [recurso eletrônico]. Santa Cruz do Sul: Editora Essere nel Mondo, 2015.

COPELLI, G. M.; LIMA, D. P. De esquerda ou de direita, a cartilha é a mesma: a Constituição. Revista Consultor Jurídico. Coluna Diário de Classe. Disponível em:https://www.conjur.com.br/2019-mar-02/ diario-classe-esquerda-ou-direita-cartilha-mesma-constituicao. Acesso em: 2 jul. 2019.

ESTADO de S. PAULO. Trump exalta carvão ao derrubar plano de Obama contra mudança climática. Disponível em: https://internacional.estadao.com.br/noticias/geral,trump-exalta-carvao-ao-derrubar-plano-de-obama-contra-mudanca-climatica,70001717693. Acesso em: 10 jan. 2019.

FREY, C. B.; OSBORNE, M. A. The future of employment: how susceptible are jobs to computerisation? Technological Forecasting and Social Change, v. 114,p. 254-280, 2017. Disponível em: http://www. sciencedirect.com/science/article/pii/S0040162516302244. Acesso em: 8 set. 2017. 
GARAPÓN, A. Le Gardien de Promesses. Paris: Odile Jacob, 1996.

GAZETA. Estatística do caos: violência no Rio é a que mais aumenta. Levantamento mostra que homicídios tiveram alta de 24\%; assaltos, de 40\%. Disponível em: https://www.gazetaonline.com.br/ noticias/policia/2018/02/estatistica-do-caos-violencia-no-rio-e-a-que-mais-aumenta-1014120694. html. Acesso em: 10 jun. 2019.

G1. Discurso xenófobo volta às ruas sem censura em vários países da Europa. Disponível em: https:// g1.globo.com/mundo/noticia/2018/08/28/discurso-xenofobo-volta-as-ruas-sem-censura-em-varios-paises-da-europa.ghtml. Acesso em: 12 jan. 2019.

G1. Por defesa de abate de suspeitos, Witzel entra na mira da PGR. Disponível em: https://noticias.uol. com.br/cotidiano/ultimas-noticias/2019/05/10/por-defesa-de-abate-de-suspeitos-witzel-entra-na-mira-da-pgr.htm?cmpid. Acesso em: 28 jul. 2019.

HABERMAS, J. Direito e democracia: entre facticidade e validade. Rio de Janeiro: Tempo Brasileiro, 1997.

HERMET, G. El populismo como concepto. Revista de Ciencia Política (Santiago), v. 23, n. 1, p. 5-18, 2003. Disponível em: https://scielo.conicyt.cl/scielo.php?pid=S0718=090-2003000100001X\&scriptsci_arttext. Acesso em: 21 fev. 2019.

LACLAU, E. On populist reason. Londres: Verso, 2005.

LACLAU, E. A razão populista. Tradução Carlos Eugênio Marcondes de Moura. São Paulo: Três Estrelas, 2013.

LIBERATI, W. D. Políticas Públicas no Estado Constitucional. São Paulo: Atlas, 2013.

MARQUES, R. M.; MENDES, Á. O social no governo Lula: a construção de um novo populismo em tempos de aplicação de uma agenda neoliberal. Revista de Economia Política, v. 26, n. 1, p. 58-74, 2006. Disponível em: http://www.scielo.br/pdf/rep/v26n1/a04v26n1. Acesso em: 20 fev. 2019.

O’DONNELL, G. Poliarquias e a (in)efetividade da lei na América latina. In: Novos Estudos. São Paulo: Cebrap, n. 5, 1998.

SOUZA, R. L. de. Populismo, mobilização e reforma. Sociedade e cultura, v. 7, n. 2, 2004. Disponível em: https://www.revistas.ufg.br/index.php/fchf/article/viewFile/986/1190. Acesso em: 14 jan. 2019.

STRECK, L. L. Hermenêutica jurídica e $(m)$ crise.: uma exploração hermenêutica da construção do Direito. 11. ed., atual. e ampliada. Porto Alegre: Livraria do Advogado Editora, 2014.

STRECK, L. L. O "pacote anticrime" de Sergio Moro e o Martelo dos Feiticeiros. Revista Eletrônica Consultor Jurídico. Disponível em: https://www.conjur.com.br/2019-fev-07/pacote-anticrime-sergio-moro-martelo-feiticeiros. Acesso em: 7 fev. 2019.

STRECK, L. L. Verdade e consenso: Constituição, Hermenêutica e Teorias Discursivas. 6. ed. São Paulo: Saraiva, 2017a.

STRECK, L. L. Dicionário de Hermenêutica: quarenta temas fundamentais da Teoria do Direito à luz da Crítica Hermenêutica do Direito. Belo Horizonte: Letramento: Casa do Direito, 2017b. 
STRECK, L. L. Jurisdição constitucional e decisão jurídica. 3. ed. São Paulo: Editora Revista dos Tribunais, 2013.

STRECK, L. L. A hermenêutica e o acontecer (Ereignen) da Constituição: a tarefa de uma nova crítica do Direito. Anuário do Curso de Pós-Graduação em Direito da Unisinos. São Leopoldo: Ed. Unisinos, 2000.

TODOROV. T. Os inimigos íntimos da democracia. Tradução Joana Angélica d'Avila Melo. São Paulo: Companhia das Letras, 2012.

WEFFORT, F. C. O populismo na política brasileira. 5. ed. Rio de Janeiro: Paz e Terra, 2003.

WIEVIORKA, M. A democracia à prova: nacionalismo, populismo e etnicidade. Tradução António Monteiro Neves. Lisboa: Instituto Piaget, 1993.

WOLFF, F. A invenção da política. In: NOVAES, A. (org.). A crise do Estado-nação. Rio de Janeiro: Civilização Brasileira, 2003.

WITTGENSTEIN, L. Investigações filosóficas. Tradução José Carlos Bruni. São Paulo: Nova Cultural, 1999. 